\title{
FORMAÇÃO, PESQUISA E PRÁTICAS NO CONTEXTO DA EDUCAÇÃO ESCOLAR INDÍGENA: AS AÇÕES DO PIBID DIVERSIDADE NO POVO XUKURU DO ORORUBÁ
}

\author{
Jaqueline Barbosa da Silva (UFPE/ \\ jaqueline.barbosa@yahoo.com.br)
}

\begin{abstract}
RESUMO
O desencadeamento do Programa Institucional de Bolsas de Iniciação à Docência para a Diversidade (Pibid Diversidade), no contexto da educação escolar indígena, anuncia estratégias de trabalho que contribui com a autonomia coletiva, o processo de construção do conhecimento e o fortalecimento da identidade étnica. Assim, o presente artigo apresenta os resultados da pesquisa Professores Indígenas de Pernambuco: formação, pesquisa e prática pedagógica (2011-2013), realizada na $1^{\mathrm{a}}$ edição do Pibid Diversidade, contextualizando a trajetória histórica do povo Xukuru e as práticas desencadeadas no âmbito da educação escolar deste grupo étnico. Logo, servimo-nos das lentes teóricas de Almeida (2017), Grosfoguel (2007) e Mignolo (2007) para explicitar o caráter epistemológico da prática pedagógica na educação escolar indígena. Essa compreensão solicitou uma metodologia filiada às perspectivas do movimento recursivo, rompendo com a linearidade colonialista das ações societárias e governamentais. A desnaturalização dos olhares viciados pela modernidade, pela colonialidade e pelo capitalismo anunciou que, as ações intervencionistas em desenvolvimento pelo público do Pibid Diversidade, no povo Xukuru do Ororubá, os processos aprendentes, formativos e paritários interrelacionam a vida das comunidades indígenas com a construção do conhecimento, reunindo escola e comunidade de modo singular e diferenciado.
\end{abstract}

Palavras-chave: Pibid Diversidade. Educação Escolar Indígena. Povo Xukuru.

\begin{abstract}
The triggering of the Institutional Program of Teaching Initiation Scholarship for Diversity (PIBID Diversity), in the context of the educational education, innovation of work with contributions with collective autonomy, process of building knowledge and strengthening ethnic identity. Thus, this article presents the results of the research Indigenous Teachers of Pernambuco: training, research and pedagogical practice (2011-2013), held in the 1st edition of Pibid Diversity, contextualizing a historical trajectory of the Xukuru people and as practices unleashed in the field of education of this ethnic group. Therefore, we use the theoretical lenses of Almeida (2017), Grosfoguel (2007), Escobar (2005) and Mignolo (2007) to make explicit the epistemological character of pedagogical practice in the indigenous school education. This understanding calls for a methodology linked to the perspectives of the recursive movement, breaking with a colonialist linearity of the societal and governmental actions. A denaturalization of the addicted looks by modernity, by qualification and by the announced capitalism, as interventionist actions in development by the public of Pibid Diversity, not the people Xukuru of Ororubá, the learning, formative and parental processes interrelate the life of the indigenous communities with the construction of knowledge, bringing together school and community in a unique and differentiated way.
\end{abstract}

Key-words: Pibid Diversity. Indigenous School Education. Xukuru People.

\section{INTRODUÇÃO}


A educação escolar dentro dos territórios indígenas no Brasil, desde o inicio da colonização, denunciava a epistemologia eurocêntrica, por privilegiar um padrão ocidental de ensino e práticas que desconsideravam o outro como sujeito de conhecimento (GROSFOGUEL, 2007). A negação dos saberes tradicionais desse povo se revelava no processo de escolarização, no que se refere ao funcionamento da escola e a construção de processos favoráveis às aprendizagens das crianças.

Durante décadas, o povo Xukuru do Ororubá ${ }^{1}$ enfrentou os parâmetros predefinidos e a pouca flexibilidade na diferenciação dos sujeitos, vivenciando uma escola de negação da identidade étnica que subordinava a educação escolar indígena à hegemonia dos fazendeiros que perseguiam, ameaçavam e controlavam as ações territoriais. Porém, a década de 80 representa um marco para a reconstrução da identidade étnica desse povo, ocasião em que uma nova liderança se inseriu no comando desse território. A escolha do líder Francisco de Assis Araújo (Xicão) fez ressurgir as identidades na política, baseada em projetos éticoepistêmicos que conta com a participação coletiva e democrática daqueles que objetivam contribuir com o fortalecimento da cultura e identidade.

O projeto "Professores Indígenas de Pernambuco: formação, pesquisa e prática pedagógica”, anunciado neste artigo, quatro anos após a sua realização, através das ações pedagógicas permitiu-nos transgredir com a lógica pré-estabelecida do Programa Institucional de Bolsas de Iniciação à Docência para a Diversidade (Pibid Diversidade). Na ocasião da segunda edição do Programa (2014-2018) foram inseridas temáticas advindas da contextualização dos conhecimentos próprios de ensino e aprendizagem, articulando a concepção de educação escolar indígena às ações intervencionistas de seus subprojetos ${ }^{2}$.

Do ponto de vista teórico-metodológico, a pesquisa utilizou três instrumentos para coleta das informações, os quais se articularam para atender as ações intervencionistas. $\mathrm{O}$ primeiro, contou com a aplicação de um diagnóstico realizado junto à comunidade escolar indígena, o qual buscou identificar o trabalho realizado nas escolas do povo Xukuru. No segundo, evidenciamos as ações intervencionistas que permearam o contexto da educação

\footnotetext{
${ }^{1}$ Este povo encontra-se localizado no agreste pernambucano, distribuídos entre os munícipios de Pesqueira e Poção.

2 A segunda edição do Pibid Diversidade, lançado através do edital 66/2013, definiu a composição de subprojetos por áreas, sendo elas: Educação do Campo; Educação do Campo - Ciências da Natureza e Matemática; Educação do Campo - Ciências Humanas e Sociais; Educação do Campo - Linguagens e Códigos; Intercultural Indígena; Intercultural Indígena - Ciências da Natureza e Matemática; Intercultural Indígena Ciências Humanas e Sociais; Intercultural Indígena - Linguagens e Códigos; e, Interdisciplinar.
} 
escolar indígena. E, o terceiro constituiu-se de um formulário submetido pela Coordenação de Aperfeiçoamento de Pessoal de Nível Superior (CAPES), a fim de avaliar o encaminhamento do Programa, através do grupo que vem participando diretamente das ações, contemplando toda equipe de trabalho, professores/as, supervisores/as e coordenações - institucional e de área. O mesmo foi composto por duas partes: 1) questões fechadas, acerca de informações pessoais e sobre o Programa; 2) priorizou questões abertas, levando o participante a avaliar o desenvolvimento das ações. O resultado desta primeira edição do Programa, orientou-nos na elaboração dos subprojetos de intervenção, levando-nos a aprovação do edital 66 (2013) ${ }^{3}$, lançado pela CAPES.

A relação de afetividade entre professores/as e estudantes, bem como a presença das lideranças no cotidiano da educação escolar indígena revela-nos o processo horizontal de construção dos conhecimentos. Assim, os desafios, outrora identificados quanto à: dificuldade de leitura e escrita, atendimento burocrático às normas do sistema-mundo europeu e validação do conhecimento pelos espaços de reconhecimento do saber, anunciam o quanto ainda temos a aprender com a pedagogia intercultural, os conhecimentos indígenas e as práticas educativas das comunidades tradicionais.

O texto está atravessado pela multiplicidade de instrumentos que contribuíram para entender a dinâmica da educação escolar indígena, inovando teórica e politicamente o atendimento a diversidade epistêmica na organização dos subprojetos de intervenção submetidos à segunda edição do Programa. Por isso, queremos afirmar que este trabalho é

\footnotetext{
${ }^{3}$ Neste edital, o Pibid Diversidade objetiva: (1) incentivar a formação de docentes em nível superior para as escolas de educação básica indígenas, do campo - incluídas as escolas quilombolas, extrativistas e ribeirinhas; (2) contribuir para a valorização do magistério intercultural indígena e em educação do campo; (3) elevar a qualidade da formação inicial de professores nos cursos das licenciaturas intercultural indígena e do campo, promovendo a integração entre educação superior e educação básica; (4) proporcionar aos licenciandos oportunidades de criação e participação em experiências metodológicas, tecnológicas e práticas docentes de caráter inovador e interdisciplinar, nas perspectivas intercultural indígena e do campo, que busquem a superação de problemas identificados no processo de ensino-aprendizagem; (5) envolver escolas públicas de educação básica de comunidades indígenas e do campo no processo de formação inicial para o magistério; (6) contribuir para a articulação entre teoria e prática necessárias à formação dos docentes, elevando a qualidade das ações acadêmicas nos cursos de licenciatura; (7) contribuir para a inserção dos estudantes de licenciatura na cultura escolar do magistério por meio da apropriação e da reflexão sobre instrumentos, saberes e peculiaridades do trabalho docente; (8) dar visibilidade à investigação docente no âmbito dos processos próprios de ensino e aprendizagem, com vistas à intervenção pedagógica no desenvolvimento de metodologias específicas para a diversidade sociocultural e linguística, na perspectiva do diálogo intercultural; (9) propiciar um processo formativo que leve em consideração às diferenças culturais, a interculturalidade do país e suas implicações no trabalho pedagógico; e, (10) contribuir para o fortalecimento das escolas por meio da reflexão crítica das atividades didático-pedagógicas, produzidas nos ambientes escolares e relacionadas às particularidades de cada comunidade ou região.
} 
resultado de uma experiência (re) construída no trajeto com os/as atores/atrizes vinculados/as ao Pibid Diversidade, especificamente, ao subprojeto Ciências Sociais e Humanas.

O trajeto compartilhado, por onde transitamos, desafiou-nos a pensar numa articulação entre a Comissão dos Professores Indígenas de Pernambuco (COPIPE) e as redes associacionistas ${ }^{4}$, exigindo respeito às vivências intervencionistas e as narrativas dos sujeitos, fazendo-nos contemplar, na $2^{\mathrm{a}}$ edição do Programa, os seguintes subprojetos: (1) Saberes tradicionais $^{5}$; (2) Língua, leitura e produção de texto ${ }^{6}$; (3) Arte indígena ${ }^{7}$; (4) Processos próprios de ensino e aprendizagem ${ }^{8}$; (5) Gestão da educação escolar indígena ${ }^{9}$; (6) Educação Inclusiva $^{10} \mathrm{e},(7)$ Bem viver e tecnologias ${ }^{11}$.

Nestes subprojetos buscam-se fomentar, junto aos sujeitos do Curso de Licenciatura Intercultural Indígena, do Centro Acadêmico do Agreste (CAA), da Universidade Federal de Pernambuco (UFPE), envolvidos no Programa, experiências que permeiem o contexto da educação escolar indígena em relação à valorização e respeito aos conhecimentos tradicionais, através de diferentes modos: valorizando e mantendo a sociodiversidade indígena, implementando a elaboração de materiais didático-pedagógicos que evidenciem e valorizem

\footnotetext{
${ }^{4}$ Estas Redes remetem-se as associações, organizações, sindicatos e movimentos sociais, configurando-se como espaços educativos e formativos de acesso à educação não escolar. Os mesmos caracterizam-se pelas relações de troca de conhecimentos, lugar de socialização e valorização dos conhecimentos, sem tentar negligenciá-los ou colonizá-los.

${ }^{5}$ Alia-se aos subprojetos Arte Indígena e Processos Próprios de Ensino e Aprendizagem, perpassando transversalmente todos os demais subprojetos, buscando contemplar a história e cultura afro-brasileira e indígena, estabelecidas na lei 10.639/2003 e 10.645/2008, a abordagem, a Política Nacional de Educação Ambiental e o Decreto N N $^{\circ} .037 / 2009$, referente ao Programa Nacional de Direitos Humanos, mobilizando e articulando as ações do Programa com as emergências da Educação Escolar Básica.

${ }^{6}$ Constitui o subprojeto de referência para o aperfeiçoamento do diálogo entre as práticas de leitura e escrita dos povos indígenas e a promoção do saber comunicativo, organizando ações que resultem na divulgação do processo de aquisição do sistema de escrita e na orientação para o aperfeiçoamento do desenvolvimento da mesma na educação escolar indígena.

${ }^{7}$ Vincula-se aos subprojetos Saberes Tradicionais e Processos Próprios de Ensino e Aprendizagem, perpassando transversalmente todos os demais subprojetos.

${ }^{8}$ Encontra-se articulado aos subprojetos Arte Indígena e Saberes Tradicionais, perpassando transversalmente todos os demais subprojetos.

${ }^{9}$ Visa estreitar a rede de relações composta pela Comunidade escolar indígena, a COPIPE e os integrantes do projeto na Universidade estabelecendo uma relação de escuta e diálogo, proporcionando reflexões e intervenções entre a Educação Básica e o Ensino Superior.

${ }^{10}$ Prioriza a perspectiva da inclusão, propiciando um processo formativo que considere as diferenças socioculturais entre os povos indígenas, a dimensão da perspectiva intercultural disponibilizando a pensar, junto ao conjunto de membros participantes, as ações que respeitem os sujeitos nas suas diferenças e especificidades, visando à expansão de práticas educativas inclusivas.

${ }^{11}$ Pretende refletir a importância dos valores e vivências dos povos indígenas, especificamente no que diz respeito à forma de vida diferenciada do "mal viver" da sociedade ocidental, visando contribuir numa educação escolar indígena própria, a cultura e as formas de vida e de saberes desses Povos.
} 
as especificidades dos saberes tradicionais das populações indígenas, visando o fortalecimento das auto identidades e da organização político-cultural desses mesmos povos historicamente silenciados.

Em sendo assim, estes subprojetos dão visibilidade ao compartilhamento das aprendizagens próprias dos povos indígenas.

\section{EDUCAÇÃO ESCOLAR INDÍGENA: INDÍCIOS DA TRANSCULTURALIDADE}

A concepção de território para os povos indígenas se diferencia do conceito jurídico. Enquanto, para os indígenas esse espaço revela “[...] um modo próprio de explicar a origem do universo e da humanidade" (OLIVEIRA, 2008: 177), no jurídico focaliza-se exclusivamente nos direitos do poder central, embora tenha uma cosmovisão diferenciada para cada povo. Essa fragmentação entre poder central/indivíduo desconsidera o lugar da natureza, a qual evidencia "[...] um arraigamento especial a um território concebido como uma entidade multidimensional que resulta dos muitos tipos de práticas e relações; e também estabelecem vínculos entre os sistemas simbólico/culturais e as relações produtivas que podem ser altamente complexas" (ESCOBAR, 2005: 66).

Para atingir essa missão, a gestão do território Xukuru foi reorganizada socialmente, contando atualmente com diferentes instâncias deliberativas, a exemplo da Equipe Jupago, Coletivo Poiá Limolaigo, Assembleia interna do povo, realizada anualmente no mês de maio, bem como, Conselhos específicos que complementam a organização social, tais como: o Conselho de Saúde (CISXO) e o Conselho de Educação Xukuru (COPIXO).

Assim, o povo Xukuru passou a potencializar novas fontes de conhecimentos dentro do seu próprio território, desempenhando diferentes funções e estratégias de organização que testemunham o exercício de autonomia no espaço de vida. Nessa direção, a instituição escolar na comunidade assume uma dupla função, articular os conhecimentos tradicionais do povo e desenvolver práticas educativas que dialoguem com as exigências da educação escolar formal e os ideais de coletividade e participação indígena.

Para que a educação escolar indígena seja realmente específica, diferenciada e adequada às peculiaridades culturais das comunidades indígenas é necessário que os profissionais que atuam nas escolas pertençam às sociedades envolvidas no processo escolar. É consenso que a clientela educacional indígena é mais bem atendida através de professores índios, que deverão ter acesso a cursos de formação inicial e 
continuada, especialmente planejados para o trato com as pedagogias indígenas (BRASIL, 1999).

Essa prerrogativa assume o princípio da educação intercultural, configurando-se numa

[...] pedagogia do encontro até suas últimas consequências, visando a promover uma experiência profunda e complexa, em que o encontro/confronto de narrações diferentes configura uma ocasião de crescimento para o sujeito, uma experiência não superficial e incomum de conflito/acolhimento" (FLEURI, 2002: 140, grifo do autor).

Para Fleuri (2002) essa perspectiva teórica compreende as relações entre diferentes dimensões das práticas humanas em contextos educativos que permitem a articulação entre os diferentes sujeitos e os contextos socioculturais há que pertencem.

Para atender as prescrições universalistas da educação escolar, os educadores Xukuru dão continuidade ao processo de escolarização através de cursos de formação inicial, ofertados no Ensino Superior ${ }^{12}$, e continuada, em nível de especialização e aperfeiçoamento, buscando se apropriar das discussões teóricas que circulam o espaço acadêmico e dar evidência ao trabalho educativo no âmbito da educação escolar indígena. Assim, compreender os princípios norteadores da educação escolar indígena significa aproximar-se da dimensão do direito, da participação e da coletividade, ambas unidas por ideais que relacionam o aspecto local, social, político, cultural, econômico e pedagógico. Esses requisitos são relevantes para evidenciar a função da escola indígena, tanto como divulgadora dos bens simbólicos, quanto fortalecedora de uma educação específica e diferenciada, particular a cada etnia.

Na América Latina, o princípio da interculturalidade é consequência dos novos desenhos globais do poder, capital e mercado. Porém, o pensamento descolonial avança, anunciando os movimentos dos povos originários de Abya Yala, nas suas lutas para garantir a sua alteridade, como sujeitos de direitos políticos, culturais e epistêmicos (MIGNOLO, 2007).

Ressaltamos que, neste caso, as experiências dos sujeitos e a compreensão de sua existência no conjunto de processos e condições objetivas, que articulam a política aos contextos de negociações, tensões, rupturas e reinvenções, caracteriza o processo educacional da educação escolar indígena.

\footnotetext{
${ }^{12}$ No povo Xukuru, 24 indígenas concluíram a Licenciatura Intercultural Indígena, do CAA/UFPE, em 2013. E, em paralelo a esta formação, havia professores/as Xukuru cursando outras licenciaturas, nas diversas áreas do conhecimento, em Instituições de Ensino Superior, pública e privada.
} 
Nesta direção, a educação escolar indígena surge com o propósito de dar continuidade ao processo de conhecimento introduzido na comunidade, possibilitando um intercâmbio entre a tradição do povo e as exigências educativas da escola. Ou seja, a instituição escolar não pode ser pensada como o único espaço de aprendizagem, assim como o professor especializado não pode ser visto como o único que transmite o conhecimento, conforme alerta-nos Brandão (2006). De fato, a educação escolar indígena busca a reafirmação social do povo, através do processo de escolarização, aliando o acesso ao saber sistematizado à tradição e cultura, pensando e planejando um projeto societário próprio com a finalidade de fortalecer a identidade étnico-cultural.

\section{ITINERÁRIO TEÓRICO-METODOLÓGICO}

O povo Xukuru do Ororubá encontra-se localizado há, aproximadamente, $215 \mathrm{~km}$ da capital pernambucana, habitando um território de 27.555 hectares, totalmente regularizado. Esse território encontra-se habitado por uma população de 11.200 índios, distribuídos em 23 aldeias, contando com 220 professores/as em atuação nas 42 escolas do povo, atendendo as modalidades de Educação Infantil, Ensino Fundamental, Educação de Jovens e Adultos, Ensino Médio e Educação Especial.

A dinâmica de trabalho inclui a visita in loco, o registro individual das atividades até a socialização das ações em roda de diálogo temática, a qual subsidia mensalmente o trabalho do grupo, propiciando uma atenção pormenorizada aos novos desenhos socioculturais. Este caminho de construção é elaborado coletivamente, utilizando-se de estratégias que considerem as especificidades e diferenças etnorraciais e socioculturais.

As sucessivas visitas ao povo permitiram outros formatos relacionais, outros modos de fazer a educação básica e, sobremaneira, construir novas identidades para o processo formativo no Ensino Superior, na medida em que os participantes revisitavam seus trajetos de vida e formação, dando-lhes outras interpretações de alcance subjetivo e intersubjetivo. Desse modo, não elegemos a priori os percursos que trilharam o desencadeamento das ações, intencionando que os/as participantes esboçassem, no transcurso da vivência, o trajeto próprio da construção dos conhecimentos.

A partir da construção coletiva, considerando os diferentes espaços educativos e a realidade específica do povo, elaboramos instrumentos para realização de diagnósticos, 
abordando o caráter sociocultural e pedagógico da educação escolar indígena. Apesar dos obstáculos, quanto à coleta e análise do material, o resultado advindo do mesmo, acerca das interfaces sociais e, sobretudo dos enfrentamentos no contexto da organização do trabalho escolar e das políticas públicas e educacionais, permitiram-nos esboçar outras referências para o processo próprio de ensino e da aprendizagem na escola indígena.

É partindo de como se aprende e ensina que surge a necessidade de sistematizar e garantir os conhecimentos construídos pelo povo na proposta de ação do Pibid Diversidade, considerando a função da escola e do ser humano que queremos em sociedade. Estes são esteios metodológicos que organizam as formações pedagógicas e os planejamentos curriculares.

Para o povo Xukuru a produção do conhecimento está ligada ao sentimento de pertencimento ao território sagrado, compreendendo a relação entre seres humanos, natureza e encantados, uma vez que, a terra vai além dos aspectos físicos, sociais e culturais. O território é um espaço que está relacionado ao universo religioso. Cabe recordar que, para os Povos indígenas, o território ${ }^{13}$ outorga o sentimento de lealdade às origens, transformando a identidade étnica em uma prática social efetiva. Ou seja, o território é à base dos planos de vida para efetiva autonomia e autodeterminação, é espaço simbólico: terra, tradições, valores, línguas, rituais e saberes, e, é referência identitária e de gestão do presente e do futuro.

É neste espaço sagrado que mantem-se os aspectos culturais que constituem as relações familiares e sociais do povo, mas também os conflitos, as mobilizações e lutas para demarcação da terra, a conquista da autonomia e a reafirmação da identidade étnica que se define como expressão coletiva do ser indígena. Os/as professores/as indígenas aproveitam todos os espaços de produção de conhecimento para sistematizar as ações intervencionistas, constituindo uma relação de mão dupla, em que a comunidade utiliza os espaços escolares para mobilizações, para a organização da luta pelo território tradicional, bem como para a demarcação da terra e o reconhecimento étnico-racial.

Desse modo, os/as indígenas-e-professores/as, universitários/as e lideranças dos povos mobilizam a participação ativa nas comunidades, evidenciando as características do jeito de ser professor/a-e-educador/a, destacando: o ser pesquisador/a da história e cultura do povo; ser conhecedor/a das tradições e nelas participar com orgulho; ter formação específica no

\footnotetext{
${ }^{13}$ Diferente da noção de territorialização, que demarca uma situação de cunho colonial, compreendida, segundo Oliveira (1998), como "[...] intervenção da esfera política que associa - de forma prescritiva e insofismável - um conjunto de indivíduos e grupos a limites geográficos bem determinados" (p. 56).
} 
campo da educação escolar indígena, partindo do princípio de que, quem faz parte da educação escolar indígena tem o comprometimento com a luta do povo e com a formação de guerreiros e guerreiras.

O pertencimento e itinerância do sujeito indígena elucidam conteúdos e práticas que lhe são apresentados durante um processo formativo vivenciado no âmbito coletivo e/ou participação nas decisões comunitárias (JOSSO, 2004). Essas vivências cotidianas vão se constituindo em experiências formativas que evidenciam identidades coletivas e aperfeiçoam o ser indígena-e-professor/a.

Nesse sentido, o núcleo das investigações-ações intervencionistas do Pibid Diversidade não fica restrito às atividades designadas para os/as bolsistas com tarefas isoladas, mas, sobremaneira, nos sujeitos, que atuando coletivamente, articulam as situações didáticas a dimensão do transculturalismo crítico $^{14}$, transformando-as em questões do conhecimento pedagógico escolar.

Os projetos são organizados a partir dos eixos norteadores do currículo da educação escolar indígena, como: Terra, Identidade, História, Organização e Interculturalidade ${ }^{15}$. Os eixos representam a organização do espaço e do tempo escolar e significam expectativas de práticas de ação política/pedagógica. Entendemos que, a abordagem transcultural, representa a dinâmica de construção do conhecimento no povo Xukuru, fortalecendo a formação de guerreiros e guerreiras. Sendo assim, professores, estudantes, lideranças e comunidade são participantes ativos dos processos de ensino-e-aprendizagem, que resultam na elaboração de diversos materiais específicos de apoio pedagógico, e entre vários, destacam-se os já sistematizados e socializados nas práticas pedagógicas do Pibid Diversidade.

Nesta edição, o Programa, atendeu oito escolas ${ }^{16}$, as quais se encontram localizadas nas seguintes aldeias: Pé de Serra dos Nogueiras, Cana Brava, Mascarenhas, Brejinho, Pé de

\footnotetext{
${ }^{14}$ Processo formativo e criativo que mobiliza, contribui, aprofunda e ressignifica os fazeres cotidianos escolares, permitindo ao sujeito da ação transitar por outros lugares, exercendo o respeito ao outro, atendendo ao princípio dialógico e participativo. De maneira resumida, a dimensão transcultural expressa uma política de convivência com a diferença e de descolonização do pensamento. Ou ainda, é o lugar sem lugar daquilo que atravessa e ultrapassa as culturas, conforme Basarab Nicolescu (2000; 2005).

${ }^{15}$ Em 2017, na ocasião da V Conferência Estadual de Educação Escolar Indígena, ocorrida nos dias 06, 07 e 08 de novembro, no hotel Canariu's de Gravatá, em Pernambuco, introduziu-se mais dois eixos: agricultura e espiritualidade, os quais se somará aos demais para articular os saberes da escola não indígena, conhecidos como "conteúdos oficiais", com os saberes da tradição Xukuru.

${ }^{16}$ Escola Antonio Feitoza Chalegre, Escola Elizeu Liberato da Silva, Escola Intermediária Monsenhor Olímpio Torres, Escola Nossa Senhora de Fátima, Escola Padre Cícero, Escola São Geraldo, Escola São João Batista e Escola São Sebastião, nessas instituições o público chega a atingir um quantitativo de aproximadamente 1.027 estudantes.
} 
Serra do Oiti, Pelada, Pão de Açúcar e Cimbres, distribuídas em três regiões do território: Agreste, Serra e Ribeira. E, os/as bolsistas acompanharam um público de 162 estudantes, contemplados por diferentes investigações-ações, abordando temáticas referentes à: instrumento de registro escolar, deficiências múltiplas, natureza sagrada, conhecimentos tradicionais, história de vida, arte e família.

A pesquisa-ação nas comunidades indígenas de Pernambuco, conta com o acompanhamento da supervisora indígena do povo que, junto ao grupo dos/as professores/asUniversitários/as, garante o encaminhamento das ações in lócus através do subprojeto: a participação do povo Xukuru na área de Ciências Humanas e Sociais do Pibid Diversidade, o qual inclui 10 ações intervencionistas, sistematizadas através da pesquisa-ação, que será apresentada na próxima parte da sistematização.

Além das ações intervencionistas, priorizamos, neste artigo, os depoimentos advindos de três questões abertas, referentes à avaliação dos resultados parciais, são elas: (1) como você avalia o Pibid para a formação profissional? (2) qual a importância do programa para a instituição e o curso de licenciatura? (3) comentários sobre observações, critérios e sugestões do mesmo.

Assim, passamos a conhecer os projetos de pesquisa-ação com as lentes das articulações e da multidimensionalidade - singular/plural, local/global, individual/coletivo.

\section{O POVO XUKURU E SUA PARTICIPAÇÃO NO PIBID DIVERSIDADE}

A discussão teórica da educação escolar indígena tem mostrado que o trabalho realizado neste território é composto por múltiplas dimensões (sócio-política-cultural e educacional), entrelaçando a vida em comunidade (ALMEIDA, 2017; TUXÁ, 2010; GRUPIONI, 2002; SILVA, 2002).

A ênfase da diversidade presente no Programa em foco, Pibid Diversidade, não retira dessa iniciativa seus aspectos seletivos e excludentes, afirmação sustentada em dados quantitativos e qualitativos quanto à restrição do público participante e, sobretudo, os padrões que orientam a aplicação dos recursos, baseados em modelos padronizados ao atendimento de uma realidade idealizada e universal, exigindo mudanças no perfil dos sujeitos atendidos, sem 
considerar a realidade e os desafios que retratam a realidade indígena de Pernambuco, particularmente, mas que não se restringe a ela, ampliando-se por todo território brasileiro.

O caráter coletivo que vem sendo assumido no desenvolvimento das ações do Pibid Diversidade, no contexto do Centro Acadêmico do Agreste da UFPE, privilegia a participação da comunidade através de suas lideranças. A análise dos diagnósticos realizados junto ao povo Xukuru e os/as bolsistas resultaram na organização dos planos de trabalho temáticos, buscando fortalecer os saberes tradicionais do povo, bem como contribuir na qualidade da educação escolar indígena.

Os projetos de pesquisa-ação foram definidos pelos bolsistas, conforme sua atuação junto aos diferentes públicos no contexto da educação escolar indígena. A organização e realização do diagnóstico consideram as "“...] experiências metodológicas, tecnológicas e práticas docentes de caráter inovador e interdisciplinar e que busquem a superação de problemas identificados no processo de ensino-aprendizagem" (BRASIL, 2010: 03) ${ }^{17}$.

Apesar do programa se voltar para a inovação e atualização do conhecimento, nessas ações o planejamento, a pesquisa e a elaboração de instrumentos vem sendo uma constante junto ao grupo dos/as Pibidianos/as. Ou seja, o envolvimento da comunidade proporciona um trabalho transdisciplinar, alcançado através de resultados advindos com a participação dos familiares e lideranças na vida escolar, acompanhando o desenvolvimento da leitura e da escrita dos estudantes, fortalecendo assim, a identidade étnica-cultural nas ações específicas do povo Xukuru.

No geral, as atividades práticas mostraram ações de mobilização no espaço da educação escolar indígena, identificadas nos instrumentos - relatórios, parcial e final, bem como das produções desencadeadas junto ao público da ação. No período de 2011-2013, havia 24 professores/as realizando a Licenciatura Intercultural Indígena ${ }^{18}$, no CAA/UFPE. Portanto, o quadro 1 apresenta, suscintamente, a área de conhecimento, projeto e contribuição/resultado da ação à ser deixada para a educação escolar indígena.

\footnotetext{
${ }^{17} \mathrm{Na}$ ocasião da abertura do referido Edital Conjunto No 002/CAPES/SECAD-MEC, em 2010, a Secretaria de Educação Continuada, Alfabetização, Diversidade (SECAD) ainda não havia incorporado a inclusão nas suas ações, sendo denominada em 2014 de Secretaria de Educação Continuada, Alfabetização, Diversidade e Inclusão (SECADI).

${ }^{18}$ Este curso faz parte do Programa de Formação Superior e Licenciaturas Indígenas (PROLIND), tornado público em 2005, através do Edital $N^{\circ}$ 05. O artigo Diversidade e Educação Escolar Indígena em Pernambuco: o Programa Institucional de Bolsas de Iniciação à Docência no contexto da UFPE, das autoras Fátima Aparecida Silva, Jaqueline Barbosa da Silva e Eliene Amorim de Almeida (2013), explicita a abrangência nacional do respectivo curso.
} 
Quadro 1- Área(s) de conhecimento, projeto(s) de investigação-ação

\begin{tabular}{|c|c|c|c|}
\hline $\begin{array}{l}\text { BOLSIST } \\
\text { A(S)/ } \\
\quad \text { SEXO }\end{array}$ & $\begin{array}{l}\text { ÁREA(S) DE } \\
\text { CONHECIME } \\
\text { NTO }\end{array}$ & $\begin{array}{l}\text { PROJETO(S) DE } \\
\text { INVESTIGAÇÃO- } \\
\text { AÇÃO }\end{array}$ & $\begin{array}{r}\text { CONTRIBUIÇÃO } \\
\text { INTERVENCIONISTA }\end{array}$ \\
\hline $\begin{array}{c}1 . \\
\text { Souza1/Feminino }\end{array}$ & $\begin{array}{c}\text { Ciências } \\
\text { Humanas e Sociais }\end{array}$ & $\begin{array}{l}\text { A MEMÓRIA DOS } \\
\text { NOSSOS TOÍPES: contos e } \\
\text { mitos do povo Xukuru }\end{array}$ & $\begin{array}{l}\text { Confecção de uma } \\
\text { cartilha de contos e mitos } \\
\text { Xukuru }\end{array}$ \\
\hline $\begin{array}{l}2 . \\
\text { Lima/Masculino }\end{array}$ & $\begin{array}{c}\text { Ciências } \\
\text { Humanas e Sociais }\end{array}$ & $\begin{array}{l}\text { AS HISTÓRIAS } \text { DE } \\
\text { VIDA DOS SUJEITOS DA } \\
\text { ALDEIA CIMBRES: uma } \\
\text { autobiografia }\end{array}$ & \begin{tabular}{lll} 
& \multicolumn{3}{c}{ Elaboração de um } \\
livro com a biografia & das \\
histórias de vida & das \\
lideranças da aldeia Cimbres
\end{tabular} \\
\hline $\begin{array}{c}3 . \\
\text { Silva1/Feminino }\end{array}$ & $\begin{array}{l}\text { Língua/Linguage } \\
\text { m e Códigos }\end{array}$ & $\begin{array}{l}\text { ARTE } \\
\text { EDUCAÇÃO INDÍGENA: a } \\
\text { musicalização no trabalho } \\
\text { com os estudantes do povo } \\
\text { Xukuru }\end{array}$ & $\begin{array}{l}\text { Produção em mídia } \\
\text { com as músicas indígenas, } \\
\text { acompanhado de um livro } \\
\text { ilustrado com a letra, } \\
\text { composição e curiosidades } \\
\text { sobre as mesmas }\end{array}$ \\
\hline $\begin{array}{c}4 . \\
\text { Marques/Feminino }\end{array}$ & $\begin{array}{l}\text { Língua/Linguage } \\
\text { m e Códigos }\end{array}$ & $\begin{array}{l}\text { A ESCOLA E OS } \\
\text { SABERES TRADICIONAIS } \\
\text { DO POVO XUKURU }\end{array}$ & $\begin{array}{l}\text { Confecção de uma } \\
\text { cartilha com desenhos e } \\
\text { textos produzidos pelos } \\
\text { estudantes }\end{array}$ \\
\hline $\begin{array}{c}5 . \\
\text { Medeiros/Feminino }\end{array}$ & $\begin{array}{l}\text { Ciências da Terra } \\
\text { e da Natureza }\end{array}$ & \begin{tabular}{lr}
\multicolumn{1}{c}{ JOGOS } & $\mathrm{E}$ \\
BRINCADEIRAS & NA \\
REALIDADE XUKURU & \\
\end{tabular} & \begin{tabular}{ll}
\multicolumn{1}{c}{ Confecção } & de \\
brinquedos tradicionais & do \\
povo Xukuru & \\
\end{tabular} \\
\hline $\begin{array}{c}6 . \\
\text { Alencar/Masculino }\end{array}$ & $\begin{array}{l}\text { Ciências da Terra } \\
\text { e da Natureza }\end{array}$ & \begin{tabular}{llr}
\multicolumn{1}{c}{ A } & FAMÍLIA NO \\
ESPAÇO DE DECISÃO \\
ESCOLAR: \\
trabalho estratégias de \\
pedagógicas da sala de aula
\end{tabular} & $\begin{array}{l}\text { Confecção de um } \\
\text { folheto tendo como conteúdo } \\
\text { estratégias para aproximar a } \\
\text { família da escola }\end{array}$ \\
\hline $\begin{array}{l}7 . \\
\text { Silva2/Feminino }\end{array}$ & $\begin{array}{l}\text { Ciências da Terra } \\
\text { e da Natureza }\end{array}$ & $\begin{array}{l}\text { INTERAÇÃO, } \\
\text { JOGOS DIDÂTICOS E } \\
\text { DEFICIÊNCIAS } \\
\text { MÚLTIPLAS: estratégias de } \\
\text { trabalho no povo Xukuru }\end{array}$ & $\begin{array}{l}\text { Confecção de jogos } \\
\text { didáticos }\end{array}$ \\
\hline $\begin{array}{c}8 . \\
\text { Souza2/Feminino }\end{array}$ & $\begin{array}{l}\text { Ciências da Terra } \\
\text { e da Natureza }\end{array}$ & \begin{tabular}{l}
\multicolumn{2}{c}{ PLANTAS } \\
MEDICINAIS E O PODER \\
DA CURA: ensino, \\
conhecimento \\
aprendizagem entre os \\
estudantes do povo Xukuru \\
\end{tabular} & $\begin{array}{l}\text { Confecção de uma } \\
\text { cartilha de receitas }\end{array}$ \\
\hline $\begin{array}{c}9 . \\
\text { Oliveira/Feminino }\end{array}$ & $\begin{array}{l}\text { Ciências da Terra } \\
\text { e da Natureza }\end{array}$ & $\begin{array}{l}\text { A } \\
\text { TRANSFORMAÇÃO DO } \\
\text { LIXO NO POVO: } \\
\text { reencantando a arte, o ensino } \\
\text { e a aprendizagem }\end{array}$ & $\begin{array}{l}\quad \text { Confecção } \\
\text { exposição de brinquedos de } \\
\text { material reciclável }\end{array}$ \\
\hline $\begin{array}{c}10 . \\
\text { Silva3/Feminino }\end{array}$ & $\begin{array}{l}\text { Ciências da Terra } \\
\text { e da Natureza }\end{array}$ & $\begin{array}{lcr} & \text { O DIÁRIO } & \text { DE } \\
\text { CLASSE NAS } & \text { ESCOLAS } \\
\text { DO POVO } & \text { XUKURU: } \\
\text { instrumento de interação e } \\
\text { intervenção do trabalho } \\
\text { pedagógico }\end{array}$ & $\begin{array}{l}\text { Confecção de um } \\
\text { diário específico para o povo } \\
\text { Xukuru }\end{array}$ \\
\hline
\end{tabular}

Fonte: Relatório final/Subprojeto Ciências Humanas e Sociais - Pibid Diversidade UFPE (2013). 
Como se pode depreender, no quadro 1, os/as bolsistas foram identificados/as pelos seus sobrenomes, o qual foi composto por uma numeração ordinal, na ocasião de duplicidade, acrescendo o sexo, para que pudéssemos manter a preservação da identidade dos/as mesmos/as. A participação no Pibid Diversidade contou com a presença de 10 bolsistas, oito do sexo feminino e dois do sexo masculino, atuando nas três áreas de conhecimento definidas pela CAPES, são elas: Ciências Humanas e Sociais; Língua/Linguagem e Códigos; e Ciências da Terra e da Natureza.

Além de uma supervisora e duas coordenadoras, uma de área e uma institucional, garantindo o desenvolvimento pedagógico e burocrático das ações. Somaram-se, a esse coletivo, as lideranças, anciãos e membros diversos da comunidade, os quais contribuíram com as ações intervencionistas desde o fortalecimento da história, através da memória e de relatos orais, passando pela relação da escola com o universo religioso e pelos aspectos físicos, econômicos, políticos, sociais e culturais, sempre num movimento circular de aprender e ensinar. Ou seja, de um saber que vem da comunidade e volta para o povo mais elaborado e sistematizado.

Os projetos de pesquisa-ação privilegiam o desenvolvimento pessoal, cultural e social, ambos acolhendo as expectativas e motivações advindas da problemática escolar, da vida cotidiana e da preservação da natureza.

Aliada a esses propósitos, os bolsistas ao término da ação se comprometem em deixar registrada sua contribuição para a organização do trabalho escolar e ao processo de ensino e aprendizagem da comunidade escolar indígena, organizando junto ao público envolvido na ação a produção e confecção de instrumentos didático-pedagógicos a serem trabalhado com crianças, jovens e adultos de diferentes níveis de aprendizagens em formato de organização diferenciados (individual, dupla, coletivo, etc.), a exemplo de: cartilhas contemplando os contos, mitos e receitas do povo, livros, CDs, brinquedos, jogos didáticos, etc. Além da contribuição deixada à organização do trabalho escolar, através de folhetos contendo estratégias de atividades que estreitem as relações família-escola, a comunidade será contemplada com a confecção de um diário de classe específico para o registro do trabalho desencadeado nas escolas pelos educadores.

As intervenções dos bolsistas são marcadas pela pluralidade de projetos imbricados na relação com (1) a natureza, (2) histórias de vida, (3) saberes tradicionais, (4) relações interpessoais e (5) a organização do trabalho escolar, as quais consequentemente revelam a 
dinâmica de vida comunitária. A dimensão da natureza é tematizada pelas plantas medicinais, na reciclagem do lixo, na arte, no conto e nos mitos indígenas ${ }^{19}$.

No projeto de pesquisa-ação "Plantas medicinais e o poder da cura: ensino, conhecimento e aprendizagem entre os estudantes do povo Xukuru", o trabalho de estudo, pesquisa, entrevista e visita junto aos mais velhos, resultou, inicialmente, na socialização dos conhecimentos apreendidos, conforme registro fotográfico da Exposição das plantas medicinais, após pesquisa na comunidade com os mais velhos e explicação dos estudantes quanto ao local de colheita, serventia e responsável pela indicação das plantas medicinais.

A discussão do meio ambiente e dos cuidados com a sua preservação se revela através do trabalho de sustentabilidade desenvolvido na pesquisa-ação A transformação do lixo no povo: reencantando a arte, o ensino e a aprendizagem. A implicação do lixo na natureza tem privilegiado ações de sustentabilidade para que a população não venha a ser prejudicada na qualidade de vida do lugar onde vive. Foi com esse intuito que o projeto em pauta mobilizou estudantes do ensino fundamental na realização de pesquisas, debates e oficinas práticas, buscando reverter ao mínimo o montante de material a ser encaminhado ao lixo.

Mesmo a natureza sendo uma fonte de vida para o povo indígena, pelas conquistas até hoje garantidas, ainda é possível observar prática de destruição. Práticas estas herdadas dos colonizadores na disputa de espaço e poder. Levando em consideração que são diversas as práticas que causam danos à natureza, a produção de resíduos sólidos foi escolhida por sua gravidade à comunidade. O trabalho se baseia em uma conscientização sobre os problemas causados pelo lixo e a reciclagem como uma solução para este problema será aliada ao processo de ensino e aprendizagem, através do uso de materiais reciclados como recurso prática para a aprendizagem dos estudantes.

Para os indígenas a terra é um "[...] patrimônio conquistado através do seu usufruto de forma ecologicamente sustentável, refletido na preservação territorial, na valorização cultural, na organização social e no modo de vida próprio" (TUXÁ, 2010: 53). Sendo assim, a execução de projetos de sustentabilidade socioambiental nas comunidades é mais do que uma base de conhecimentos relacionados ao meio ambiente e à sociedade. Segundo Gadotti (2007) “[...] ela deve ocupar-se da aprendizagem de atitudes, perspectivas e valores que orientam e impulsionam as pessoas a viverem suas vidas mais sustentavelmente" (p. 79).

\footnotetext{
${ }^{19}$ Para os indígenas o mito é uma história relacionada à tradição oral, sendo protagonizado pelas forças da natureza e aspectos gerais da condição humana.
} 
O envolvimento da comunidade é marcado pela interação entre os pares, somando-se a atenção e cuidado dos estudantes na manipulação do material que serve de apoio para a construção dos objetos. Compreende-se, portanto, que a educação a partir desse princípio não se reduz apenas à transmissão de conhecimentos, esta consiste na recriação de contextos educativos de interações culturais.

Quanto à pesquisa-ação, “Arte e educação indígena: a musicalização no trabalho com os estudantes do povo Xukuru", trata a arte como expressão da história de resistência do povo, enfatizando a música como uma das linguagens simbólica dessa luta. O foco da ação destinarse-á integração do ensino da arte no âmbito escolar no povo Xukuru, investigando como os educadores de arte vêm garantindo o ensino e aprendizagem da arte Xukuru no conteúdo de musicalização.

A discussão e organização do planejamento coletivo junto aos educadores de arte indígena foi uma das primeiras etapas desse trabalho. Afinal, a prática educativa que vem sendo desencadeada constitui um dos lastros dessa formação, pois, a música indígena não é apenas um produto, ou simples obra de arte, mas algo ligado às necessidades culturais significativas na vida do povo, contemplando os costumes e tradições de uma geração.

Os/as professores/as indígenas junto ao coletivo dos estudantes e lideranças vivenciam rituais próprios do povo, articulando-os ao conteúdo escolar e assim demarcam a importância milenar de suas artes, que tem na mística religiosa das canções dos toantes e da batida do jupago o respaldo da resistência ao processo de colonização.

O conto e os mitos do povo são retratados da pesquisa-ação "A memória dos nossos toípes (mais velhos)". A participação da comunidade é representada pela presença das lideranças e mais velhos, que através de conversas informais, seguem socializando seus saberes junto ao público da ação. Nos chama a atenção às atitudes de assessoramento, disponibilidade e participação entre o coletivo da comunidade, não havendo distinção entre os detentores do saber tradicional e aqueles que se encontram em processo de aprendizagem.

$\mathrm{O}$ assento das histórias de vida entre os objetos de pesquisa e intervenção revela o olhar cuidadoso e de reconhecimento da comunidade nas conquistas desse povo. A narrativa (auto) biográfica dos moradores da aldeia Cimbres contempla mais uma investigação-ação. Para Suaréz (2014) as práticas (auto) biográficas ativam a imaginação pedagógica no campo da formação e desenvolvimento profissional docente, demarcando uma formação centrada no sujeito do conhecimento. 
Este reconocimiento público y especializado de las diferentes trayectorias educativas, de formación y profesionales y la visibilización de los múltiples y locales "saberes de oficio" recreados en esos recorridos singulares, fueron la puerta de entrada para la revalorización pedagógica de los sujetos de la formación docente y, a través de ella, para la activa recuperación de los procesos de biografización en las prácticas institucionales de formación (SUARÉZ, 2014: 772-773).

Vale ressaltar que, as experiências de investigação-ação, que exploram a narrativa (auto) biográfica, ainda em consolidação no âmbito acadêmico, desafiam-nos a inserir esta temática no processo de produção de conhecimento ${ }^{20}$.

Os saberes tradicionais são retratados na pesquisa-ação que vincula a escola a esses saberes através dos costumes, festejos e danças próprias do povo. O foco nos jogos introduzidos no contexto da educação escolar indígena vincula-se com os brinquedos e brincadeiras da realidade Xukuru, buscando estreitar a relação escola-comunidade na prática educativa resgata a visita ao terreiro sagrado. O resgate da vivência no espaço sagrado aborda o reconhecimento de pertença, sendo o terreiro um dos lugares de referência das práticas sagradas, reafirmando o enraizamento e pertencimento de um povo.

Nesse caso específico, o projeto privilegia em uma das suas ações a prática do Toré como a materialização de uma religião indígena que consiste em " [...] uma dança coletiva que pode contar com um número indefinido de participantes, que se apresentam em parte pintados de branco, segundo motivos gráficos muito simples e em parte (nesse caso, apenas os homens) mascarados" (ARRUTI, 2004: 06). Vale ressaltar que o Toré tem um lugar central no desempenho da mística da etnicidade, fornecendo a legitimação etnológica, o fundamento mítico-ritual da etnogênese, e, a expressão obrigatória da indianidade.

Nos aspectos que introduzem as dimensões das relações interpessoais a presença da família na escola surge como um dos elementos fundamentais, sendo contemplada na ação "A família no espaço de decisão escolar", a qual buscou abordar as estratégias de trabalho utilizadas junto aos sujeitos, nas ações pedagógicas da sala de aula, buscando estreitar a relação família-escola-e-comunidade. Quanto à organização do trabalho escolar, o foco pedagógico inclui o olhar atento às diferenças, através da presença de crianças com deficiências múltiplas e a reformulação do instrumento de registro do ensino e aprendizagem dos estudantes.

\footnotetext{
${ }^{20}$ No Brasil, o Congresso Internacional de Pesquisa Autobiográfica representa a consolidação da temática na área da Educação. Para maiores informações ver: Modos de viver, narrar e guardar: diálogos cruzados sobre pesquisa (auto) biográfica (Mignot e Souza, 2015).
} 
No projeto "Interação, jogos didáticos e deficiências múltiplas" a escola junto aos educadores é desafiada a trabalhar de forma interativa com os estudantes que apresentam esse tipo de deficiência. Nessa investigação a educadora/bolsista vivencia uma prática criativa que garanta a inclusão e interação do grupo-classe. Como inclusão e exclusão são facetas de uma mesma realidade, discutir mecanismos para viabilizar a inclusão social através do contexto escolar faz admitir uma lógica intrinsecamente excludente, presente nos atuais modos de organização, e que se quer modificar. Isso mostra que, vivenciar ações de mobilização junto às pessoas com deficiências exige, sobretudo, a percepção e mobilização de um coletivo, seja pensando, seja produzindo, seja sensibilizando as possíveis convivências.

Já o projeto "O diário de classe nas escolas do povo Xukuru” introduz a possibilidade de uma revisão no instrumento de registro escolar, buscando assegurar a abordagem dos saberes escolar e tradicional.

O conjunto dessas produções foi assegurado pelo olhar atento do/a professor/a e a rede associacionista que interage com o povo e Programa, permitindo vislumbrar a dimensão de participação arraigada pela sensibilidade da experiência na atividade do/a professor/a-epesquisador/a. Quanto às observações, na organização coletiva da comunidade, aliamos as pesquisas-ações desenvolvidas in lócus, por possibilitar-nos o repensar da política educacional, advinda em formato de programas e com exigências burocráticas, quanto ao registro pré-determinado de conteúdos que não contemplam as aprendizagens a partir das demandas específicas dos povos indígenas.

No que se refere aos/as educadores/as, deparamo-nos com o questionário de avaliação do Pibid, pela CAPES, para o qual houve um posicionamento favorável em relação a sua contribuição para a formação profissional. Para os/as educadores/as indígenas, o programa tanto fortalece, quanto contribui com o processo de ensino e aprendizagem, indicando uma melhoria na atuação profissional, expressa nos seguintes depoimentos:

Para mim, o Pibid é um processo educacional que fortalece minha forma de ensinar, contribuindo na aprendizagem dos estudantes. Ou seja, o mesmo reforça os conhecimentos adquiridos no espaço acadêmico e em relação ao próprio povo (depoimento de Lima, bolsista de iniciação à docência do Pibid Diversidade/UFPE).

O Pibid tem contribuído no aprofundamento da pesquisa e na melhoria do ensino junto ao grupo-classe. E assim, possibilita a melhoria profissional e a qualidade da educação (depoimento de Oliveira, bolsista de iniciação à docência do Pibid Diversidade/UFPE). 
A presença do Pibid Diversidade possibilitou a renovação do trabalho no espaço da sala de aula, incluindo novas metodologias que fortalecem os conhecimentos do povo Xukuru (depoimento de Marques, bolsista de iniciação à docência).

[...] está sendo de suma importância, seja oportunizando reflexões acerca dos conhecimentos próprio do povo (Xukuru), seja possibilitando a realização de investigações de saberes até então desconhecidos (depoimento de Souza2, bolsista de iniciação à docência do Pibid Diversidade/UFPE).

No depoimento da supervisora do povo Xukuru os desejos e solicitações dos educadores são reafirmados quando a mesma considera que o referido programa "[...] estimula o professor a buscar alternativas que qualifique a educação dos estudantes da Educação Básica" (depoimento de Alencar, supervisora do Pibid Diversidade/UFPE).

Ainda, destacamos a importância do Pibid Diversidade, quando anuncia a possibilidade de estreitamento entre a Educação Básica e a formação inicial, através da Licenciatura Intercultural Indígena, visto como uma articulação que contribui para o aperfeiçoamento dos saberes teórico e prático, bem como para a formação de pesquisadores iniciantes, quando afirmam que:

[...] oferta subsídios para desenvolver os projetos na comunidade escolar indígena, os quais não seriam possíveis só com a vivência da formação inicial no curso de Licenciatura em Educação Intercultural Indígena da UFPE (depoimento de Silva2, bolsista de iniciação à docência do Pibid Diversidade/UFPE).

[...] proporciona aos estudantes novas descobertas e interesses de pesquisa (depoimento de Souza2, bolsista de iniciação à docência do Pibid Diversidade/UFPE).

[...] contribui na formação de docentes pesquisadores (depoimento de Medeiros, bolsista de iniciação à docência do Pibid Diversidade/UFPE).

Possibilita um diagnóstico preciso entre os saberes acadêmicos e práticos (depoimento de Silva1, bolsista de iniciação à docência do Pibid Diversidade/UFPE).

A supervisora da área de Ciências Humanas e Sociais afirma que o Programa,

[...] estreita a relação entre o mundo acadêmico e a realidade da comunidade indígena [...] possibilitando aos estudantes e profissionais o desenvolvimento de um trabalho que qualifique o ensino e garanta a aprendizagem do público que frequenta o espaço escolar (depoimento de Alencar, supervisora do povo do Pibid Diversidade/UFPE).

Em síntese, os/as educadores/as afirmam que o Pibid Diversidade é uma oportunidade de diálogo entre o espaço acadêmico e a comunidade escolar indígena, seja desenvolvendo 
práticas já consolidadas, seja inovando e articulando os saberes e as experiências advindas da continua disputa teoria-prática, consolidando o respeito às diferenças da diversidade étnica local nos resultados das ações que vem sendo desencadeadas no território indígena Xukuru.

Diante desse discurso as observações, críticas e sugestões ao programa se destinam em pautas de troca de experiências e continuidade do trabalho, conforme afirmam os depoimentos que se seguem:

[...] encontro de troca de experiências entre os estudantes das diferentes IES que vivencias o Pibid Diversidade no País (depoimento de Lima, bolsista de iniciação à docência do Pibid Diversidade/UFPE).

[...] intercâmbio entre os estudantes da UFPE e demais IES que vivenciam o Pibid Diversidade no País (depoimento de Oliveira, bolsista de iniciação à docência do Pibid Diversidade/UFPE).

Continuidade do trabalho entre a Coordenação e Supervisão de área no processo de orientação, elaboração das pesquisas, planejamento e desenvolvimento das ações no interior das escolas (depoimento de Silva2, bolsista de iniciação à docência do Pibid Diversidade/UFPE).

Esses desejos se traduzem na torcida da supervisão pela permanência da ação, ao desejar "[...] que o programa tenha continuidade, oportunizando a inserção de novos docentes e estudantes na vivência dessa experiência" (depoimento de Alencar, supervisora do povo).

Em síntese, a prática educativo-pedagógica, desencadeada no processo de ensino e aprendizagem da educação escolar indígena, revela-se como sendo o lastro que sustenta a continuidade das ações nessa localidade, constituindo as possibilidades de ressignificação no processo de escrita, leitura e organização social, bem como de mudança de atitudes na relação com a mãe natureza e no fortalecimento do processo identitário do povo, protagonizando o alcance de possíveis mudanças neste território.

\section{BREVES CONSIDERAÇÕES}

Os resultados da primeira edição do Programa revelaram mudanças na postura e prática educativo-pedagógica dos/as professores/as, seja dinamizando as aulas, seja motivando o desenvolvimento da leitura e da escrita dos estudantes, aproximando os estudantes, lideranças, professores/as e comunidade das discussões que cercam o planejamento e o desenvolvimento das ações pedagógicas na educação do povo. 
Os/as professores/as ao dialogarem com os mais velhos da comunidade, no desenvolvimento de ações junto aos estudantes, garantem o processo participativo e fortalecem a construção permanente da identidade étnica.

Porém, os desafios ainda perduram, abrigando contradições que impedem o cumprimento do compromisso, constatando nos depoimentos dos/as professores/as, a saber: ausência de uma equipe permanente e específica na orientação do trabalho com os portadores de deficiências múltiplas; receios, por parte dos/as professores/as externos ao Programa, quanto à disponibilidade de informações que revelem as estratégias de invisibilidade no trato ao conhecimento escolar frente às exigências burocráticas no registro do diário de classe, entre outros.

Por fim, embora o Pibid Diversidade reconheça a existência de um contexto diferenciado, seus princípios se mantêm interligados a epistemologia eurocêntrica do sistemamundo moderno/colonial, desafiando o grupo dos/as Pibidianos/as na realização das ações junto às comunidades indígenas de Pernambuco.

\section{REFERÊNCIAS}

ARRUTI, José Maurício. 2004. "A produção da alteridade: o Toré como código das conversões missionárias e indígenas". Anais do VII Congresso Luso-Afro-Brasileiro de Ciências Sociais - A questão social no novo milênio, Coimbra/Portugal.

ALMEIDA, Eliene Amorim. 2017. A interculturalidade no currículo da formação de professoras e professores indígenas no Programa de Educação Intercultural da UFPE/CAA Curso de Licenciatura Intercultural. Tese de Doutorado em Educação, Universidade Federal de Pernambuco.

BRANDÃO, Carlos Rodrigues. 2006. O que é educação. 48ª ed., São Paulo, Brasiliense.

BRASIL. 1999. Parecer $n^{\circ}$ 14/Conselho Nacional de Educação, Brasília/DF. 2010. Edital Conjunto $N^{o}$ 002, CAPES/SECAD-MEC, Brasília/DF.

ESCOBAR, Arturo. 2005. "O lugar da natureza e a natureza do lugar: globalização ou pósdesenvolvimento? A colonialidade do saber: eurocentrismo e ciências sociais." Perspectivas latino-americanas, CLACSO, Ciudad Autónoma de Buenos Aires/Argentina.

FLEURI, Reinaldo Matias. 2002. Desafios à educação intercultural no Brasil. Intercultura: estudos emergentes. Ijuí, Rio Grande do Sul, UNIJUÍ. 
GADOTTI, Moacir. 2007. "Educação para o desenvolvimento sustentável: o que precisamos aprender para salvar o planeta." Revista da FAEEBA: educação e contemporaneidade, Salvador, 16 (28): 69-90.

GROSFOGUEL, Rámon. 2007. "Dilemas dos estudos étnicos norte-americanos: multiculturalismo identitário, colonização disciplinar e epistemologias descoloniais." Revista Ciência e Cultura, São Paulo, 59 (2): 32-35.

GRUPIONI, Luís Donisete Benzi. 2002. "Educação e povos indígenas: construindo uma política nacional de educação escolar indígena." Revista Brasileira de Estudos Pedagógicos, 81(198), Brasília/DF: INEP.

JOSSO, Marie-Christine. 2004. Experiências de Vida e Formação, São Paulo, Cortez.

MIGNOLO, Walter. 2007. "El Pensamiento Decolonial. El Giro Decolonial: reflexiones para una diversidad epistémica más allá del capitalismo global." Bogotá, Siglo del Hombre Editores. pp. 25-46.

NICOLESCU, Basarab et al. 2000. Educação e transdisciplinaridade. Brasília, DF, UNESCO.

NICOLESCU, Basarab. 2005. O Manifesto da Transdisciplinaridade. 3. ed. São Paulo, Triom.

OLIVEIRA, Paulo Celso de. 2008. "Gestão territorial indígena: perspectivas e alcances." Estudos indígenas: comparações, interpretações e políticas, Série Justiça e Desenvolvimento, SP, Contexto, pp. 175-191.

SILVA, Rosa Helena Dias da Silva. 2002. "O Estado brasileiro e a educação (escolar) indígena: um olhar sobre o Plano Nacional de Educação." Revista Tellus, Campo Grande/MS, 2: $123-136$

SUÁREZ, H. Daniel. 2014. "Espacio (auto) biográfico, investigación educativa y formación docente en Argentina: un mapa imperfecto de un territorio en expansión.” Revista Mexicana de Investigación Educativa, 19 (62): 763-786.

TUXÁ, Rosilene Cruz de Araújo. 2010. "Gerenciamento da educação escolar indígena, poder público e a relação com o movimento indígena: experiência e reflexão." Revista da FAEEBA Educação e contemporaneidade, UNEB: Salvador/BA, 19 (33): 51-60. 